\title{
Is the development of obesogenic food environments a self-reinforcing process? Evidence from soft drink consumption
}

\author{
Fabrizio Ferretti ${ }^{1,2^{*}}$, Michele Mariani ${ }^{1,2}$ and Elena Sarti ${ }^{1,2}$
}

\begin{abstract}
Background: Understanding how the development of obesogenic food environments and the consumption of ultra-processed foods and beverages influence each other can help policymakers to identify effective ways to curb the current obesity epidemic. This paper was designed to investigate whether, and to what extent, the consumption of soft drinks and the prevalence of obesity are linked through feedback effects.
\end{abstract}

Methods: An ecological study design and a simultaneous equation model were used to investigate the existence of a vicious cycle between the consumption of soft drinks and the prevalence of obesity. The analysis was based on a longitudinal dataset covering per capita sales of soft drinks, the age-standardised prevalence rate of obesity and several demographic and socio-economic control variables in a sample of 98 countries worldwide for the period 2005-2019.

Results: Using a Two-Stage Least Squares (2SLS) regression model with fixed effects, we documented a selfreinforcing process that links consumption and obesity. Changes in the spread of obesity were associated with changes in soft drink consumption: a one-unit increase in the age-adjusted prevalence rate of obesity increased consumption by about 2.39 I per person per year. Similarly, as the consumption of soft drinks rose, so did the prevalence of obesity: the age-adjusted rate of obesity increased by $0.07 \%$ for every additional litre consumed per capita. Computing the impact multipliers, we found that the outcome of a one-unit decrease in the average price of soft drinks was twofold: a) the prevalence of obesity increased by around $0.17 \%$; and b) consumption increased by around $2.40 \mathrm{I}$ per person, the sum of the increase directly caused by the price reduction ( $2 \mathrm{I})$ and the increase due to the interplay between consumption and obesity (0.4 I).

Conclusions: This study has identified a feedback loop between unhealthy habits (i.e. the consumption of soft drinks) and health outcomes (i.e. the prevalence of obesity). This interplay amplifies the impact of any exogenous changes in the determinants of consumption and obesity. These feedback effects should be considered and exploited in planning effective strategies to tackle the burden of obesity and the global epidemic of noncommunicable diseases.

Keywords: Cross-country longitudinal dataset, Obesity, Obesogenic environments, Soft drinks, Simultaneous equation model

\footnotetext{
*Correspondence: fabrizio.ferretti@unimore.it

'School of Social Sciences, University of Modena and Reggio Emilia, Reggio Emilia, Italy

${ }^{2}$ Department of Communication and Economics, Viale Allegri 9, 42121

Reggio Emilia, Italy
}

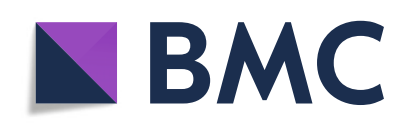

C C The Author(s). 2021 Open Access This article is licensed under a Creative Commons Attribution 4.0 International License, which permits use, sharing, adaptation, distribution and reproduction in any medium or format, as long as you give appropriate credit to the original author(s) and the source, provide a link to the Creative Commons licence, and indicate if changes were made. The images or other third party material in this article are included in the article's Creative Commons licence, unless indicated otherwise in a credit line to the material. If material is not included in the article's Creative Commons licence and your intended use is not permitted by statutory regulation or exceeds the permitted use, you will need to obtain permission directly from the copyright holder. To view a copy of this licence, visit http://creativecommons.org/licenses/by/4.0/. The Creative Commons Public Domain Dedication waiver (http://creativecommons.org/publicdomain/zero/1.0/) applies to the data made available in this article, unless otherwise stated in a credit line to the data. 


\section{Background}

According to the World Health Organization (WHO), obesity is a major preventable risk factor for several chronic non-communicable diseases (NCDs), such as cardiovascular diseases (mainly heart disease and stroke), diabetes, musculoskeletal disorders (especially osteoarthritis) and some type of cancers [1]. In addition, recent evidence also suggests that obesity is an important parameter for Coronavirus Disease 2019 (COVID-19) risk assessment because obesity and obesity-related morbidities tend to increase the risk of severe COVID-19 outcomes including admission to Intensive Care Units (ICUs) and are associated with higher fatality rates [2].

A wide range of interrelated physical, cultural, and socio-economic factors can promote unhealthy weight gain as a result of excessive energy intake and/or insufficient physical activity [3]. People's exposure to these factors has increased dramatically over recent decades in advanced and emerging economies $[4,5]$. Because of the spread of the so-called obesogenic environments $[4,6]$, the worldwide prevalence of obesity has nearly tripled since the middle of the 1970s. Obesity has now become an impending global health challenge [7].

A large and growing body of literature has investigated the impact of single nutrients and different dietary patterns on unhealthy increases in weight status, focusing mainly on the role of ultra-processed foods and beverages $[8-10]$. These are usually calorie-dense productshigh in salt, refined carbohydrates, free sugars, unhealthy fats, and additives-and their widespread availability is a prominent feature of the current obesogenic food environments $[11,12]$.

In this literature, the direction of causality runs from consumption to obesity; that is, variations in consumption of ultra-processed foods and beverages (the independent variable) are used to explain changes in weight status (the dependent variable) by controlling for the effects of several possible confounding factors. Conversely, the existence of a two-way relationship between the consumption of ultra-processed products and the prevalence of obesity remains largely unexamined.

However, there are reasons to suspect that the causality between the development of an obesogenic environment and the prevalence of obesity may run in both directions, meaning that the spread of obesogenic factors and the spread of obesity tend to reinforce one other. The sharp increase in the worldwide prevalence of obesity, for instance, seems to be driven by a self-sustaining process, as shown in Fig. 1A and B. These figures display data concerning the age-standardised prevalence rate of obesity (in people aged 18 years and over) in 190 countries, grouped according to the WHO's six world regions. During the period 1985-2015 (Fig. 1A), increases in the prevalence of obesity (measured on the y-axis) were positively related to their starting levels (measured on the x-axis, by the 1980-1985 average). Except for a few European countries (some of the orange dots), nations with the highest prevalence rate in the period 1980-1985 have experienced the greatest increases in the spread of obesity from 1985 to 2015. Moreover, in Fig. $1 \mathrm{~B}$, changes in the prevalence of obesity during the period 1980-1997 are plotted against their changes over the next 18 years (1998-2015). The data points lie substantially above the 45-degree dashed line for almost all countries, indicating that increases in the prevalence of obesity were associated with further and even greater increases.

A possible explanation for this evidence is the existence of a vicious cycle [13]. An adverse feedback loop, wherein the adoption of unhealthy habits increases the prevalence of obesity, which in turn promotes the spread of obesogenic factors, which leads to further increases in unhealthy habits, and so on. This hypothesis suggests the following research question: Is the development of an obesogenic food environment a self-reinforcing process? In this paper, we attempt to address this issue by focusing on the role of soft drinks.

The term 'soft drinks' generally refers to a wide range of non-alcoholic carbonated and non-carbonated waterbased (or, in some cases, milk-based) flavoured drinks, usually added with sugar or other natural and artificial sweeteners [14]. Soft drinks are ubiquitous in modern food environments [15]. Their regular consumption has been associated with an increased risk of adverse health outcomes, including overweight and obesity, type 2 diabetes, and heart diseases [16]. This is because the vast majority of soft drinks are high in free sugars and various additives, but also because they usually serve as complement-in-consumption of ultra-processed unhealthy foods and snacks [17-19].

The purpose of this study is to investigate the existence of a vicious cycle between the consumption of (and thus the demand for) soft drinks and the prevalence of obesity. To this end, we use an ecological study design and a simultaneous equation model. The analysis is based on a longitudinal dataset covering per capita consumption of soft drinks, the age-standardised prevalence rate of obesity, as well as other demographic and socioeconomic control variables in a sample of 98 countries worldwide for the period 2005-2019.

We build on previous research based on similar crosscountry datasets. These studies have examined the association between the consumption of soft drinks (their prices and affordability) and the prevalence of obesity [20-22]. More recently, research has begun to examine the impact of obesity in determining the market demand for soft drinks [23]. However, what remains unclear is whether, and to what extent, the consumption of soft 

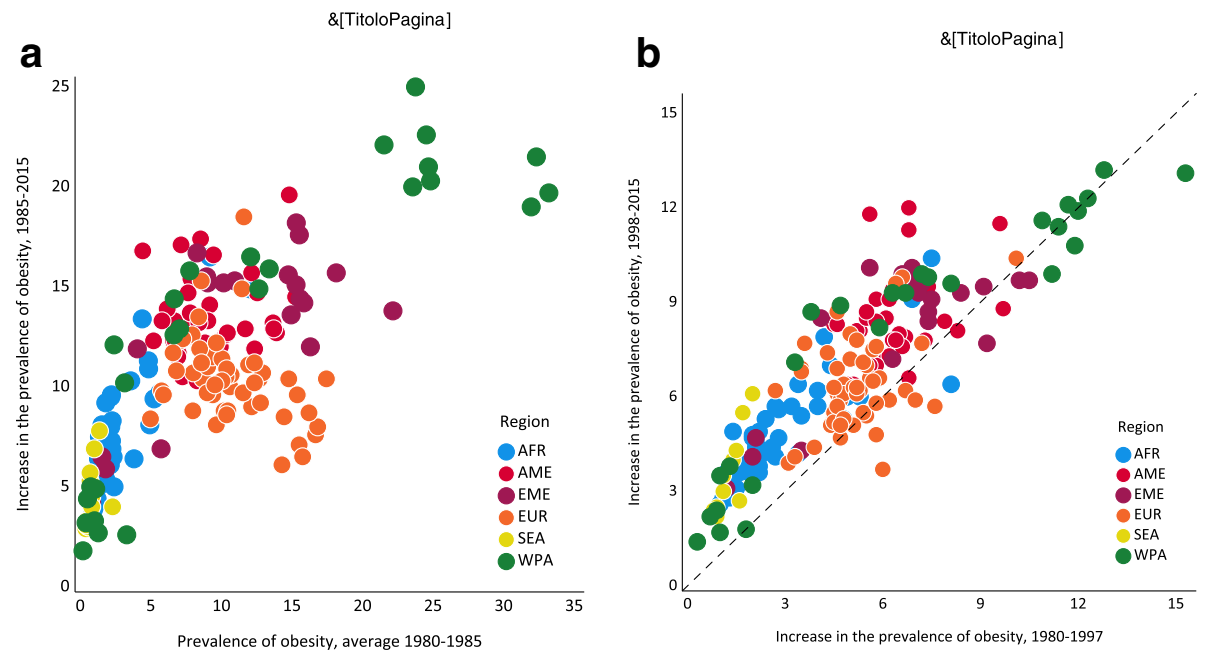

Fig. 1 A. Prevalence of obesity (average levels 1980-85 and increases 1985-2015). B. Increase in the prevalence of obesity (1980-1997 and 19982015). Legends: Prevalence of obesity (Age-stand. Rate, both sexes, 18+ years, \%)

drinks and the prevalence of obesity influence each other through feedback effects that trigger a self-reinforcing process. Unlike these previous studies, in this paper, we model the relationship between soft drinks and obesity using a simultaneous equation approach. Understanding and measuring the role of potential feedback effects may be helpful in the design of a better comprehensive strategy to curb soft drink consumption and tackle the current obesity epidemic [24].

\section{Methods and data}

This study set out to test the hypothesis that the consumption of soft drinks and the prevalence of obesity are jointly determined. A simultaneous equation model can capture this idea as follows:

$$
\begin{aligned}
& Q S D=a_{0}+a_{1} O B E+a_{2} X_{1}+a_{3} X_{2}+\ldots+a_{n} X_{n} . \\
& O B E=b_{0}+b_{1} Q S D+b_{2} X_{2}+b_{3} X_{3}+\cdots+b_{n} X_{n} .
\end{aligned}
$$

where $Q S D$ and $O B E$ denote the per capita consumption of soft drinks and the prevalence of obesity, respectively. In these two structural equations, the variables $Q S D$ and $O B E$ are simultaneously determined (i.e. they are both endogenous), whereas the $X s$ represent demographic and socio-economic exogenous control variables that may affect either or both $Q S D$ and $O B E$. In other words, a change in soft drink consumption (Eq. 2) will cause a change in the prevalence of obesity, which will, in turn, cause soft drink consumption to change again (Eq. 1), and so forth. Likewise, a change in the prevalence of obesity, in Eq. 1), will lead to a change in soft drink consumption that, through Eq. 2), will trigger a feedback loop that promotes further changes in both the prevalence of obesity and the consumption of soft drinks. Conversely, a change in an exogenous variable (for example, $X_{1}$ ) will not loop back through the system and cause $X_{1}$ to change again.

\section{Data sources}

In order to develop the empirical analysis, we collected secondary data from the following five sources: Euromonitor International, the World Health Organisation (WHO), the World Bank Group (WBG), the United Nations Food and Agriculture Organisation (FAO), and the KOF Swiss Economic Institute.

Passport, the Global Market Information Database of Euromonitor International [25], contains information about sales, in both volume and value, of the different types of soft drinks for a large number of countries worldwide. From this dataset, we computed the soft drink consumption per capita $(Q S D)$ and the average price of soft drinks (PSD) in 98 countries from 2005 to 2019.

Specifically, QSD was obtained by dividing the total sales in volume of both non-carbonated (i.e. fruit juices, ready-to-drink tea, and coffee, as well as sports/energy and Asian drinks) and carbonated (i.e. regular and diet sodas) soft drinks by the total country population. QSD is measured in litres per person per year and includes on-trade and off-trade sales of both domestically manufactured and imported beverages (but it does not include bottled (carbonated and still) water).

Similarly, we computed the average price of soft drinks $(P S D)$ as the ratio of total sales in value to total sales in volume. Prices measured in local currencies were thus 
converted to international dollars-using purchasing power parity (PPP) conversion factors, provided by the International Comparison Program of the World Bank [26] - and expressed in 2017 constant prices to allow comparability across countries and over time. PSD is the average retail selling price per litre, including sales and excise taxes.

The Global Health Observatory [27] of the World Health Organization (WHO) collects comparable estimates of the prevalence of overweight and obesity for almost all countries worldwide. From this data repository, we retrieved the age-standardised adjusted estimates of the prevalence of overweight and obesity $(O W E$ and $O B E)$ among the adult population. The variables $O W E$ and $O B E$ are measured by the percentage of adults (aged 18 years or older) who have a body mass index (BMI) equal to or greater than 25 and $30 \mathrm{~kg} / \mathrm{m}^{2}$, respectively (where BMI is defined as weight in kilograms divided by the square of height in metres).

From the World Bank Open Data repository [28], data were gathered for the following three variables: income per capita $(G N I)$, the share of the population aged 65 and above $(A G E)$, and the ratio of urban to total population $(U R B)$. It has previously been observed that soft drink affordability-defined as the ratio between the average price of soft drinks and the income of potential consumers-is one of the major factors affecting purchasing behaviour $[22,29]$. Besides the market price, data on Gross National Income per capita (GNI, measured in constant 2017 international dollars) were thus included in the analysis to account for overtime withincountry differences in average income (and, ultimately, in standards of living).

The share of elderly people, measured by the number of people aged 65 and above as a percentage of the total population $(A G E)$, was included as a demographic driver of both soft drink consumption and population health outcomes. On the one hand, soft drinks are popular beverages, especially among children, adolescents, and young adults, who usually represent the populations targeted by the soft drink industry with aggressive marketing strategies [30,31]. On the other hand, although the prevalence of obesity among children and adolescents has risen dramatically over the last decades, the number of elderly individuals with obesity has also increased, and it is expected to increase further as the population ages, mainly in emerging economies [32]. Therefore, increases in the share of elderly people should decrease the consumption of soft drinks and increase the prevalence of obesity.

As highlighted by prior research [33], economic and social structural changes, such as the increasing number of people who live in urban areas, typically lead to more sedentary lifestyles and consequently to a decreasing home and occupational energy expenditure. Thus, the share of urban to total population $(U R B)$ was used here as a proxy variable to capture in Eq. 2) these potential drivers of the obesity pandemic.

Starting from national balance food sheets, the Food and Agriculture Organization (FAO) of the United Nations [34] computes the dietary energy supply $(D E S)$. These are estimates of the average number of calories available for human consumption in each country (measured in kcal per person per day). An increased food energy supply has been associated with the spread of unhealthy increases in population body weight [8]. Therefore, we used these internationally comparable DES estimates to capture the impact of changes in food availability on the prevalence of obesity.

Finally, the KOF Swiss Economic Institute [35] has developed an index to measure the overall degree of globalisation, and sub-indices to measure the degree of the different (i.e. economic, political, etc.) dimensions of the globalisation process. In the soft drink industry, large multinational companies and specialised local firms compete in a global business environment [36]. International trade and foreign direct investment tend to increase the supply and variety of soft drinks available to consumers, whereas global advertising strategies may affect people's health-related lifestyles [37]. We considered the role of these processes in shaping modern obesogenic environments by including the KOF Index of economic globalisation among the exogenous control variables as a potential determinant of both the consumption of soft drinks and the spread of obesity.

Overall, we collected data about nine variables-the consumption of soft drinks per capita (QSD), the agestandardised prevalence rate of overweight and obesity $(O W E$ and $O B E)$, the average price of soft drinks (PSD), the gross national income per capita $(G N I)$, the dietary energy supply $(D E S)$, the share of urban population $(U R B)$, the share of the elderly population $(A G E)$, and the degree of economic globalisation $(G L O)$-from 98 countries, where each country is observed in $t=15$ time periods (each year from 2005 to 2019), for a total of 1470 observations. Hong Kong and Taiwan, however, were omitted from the regression analysis due to incomplete information on several variables. The resultant dataset is a balanced panel data containing 1440 observations.

A short description of each variable, along with basic descriptive statistics, is shown in Table 1. A list of the countries included in the analysis is shown in Table 1A in the Supporting Information File S1. For the entire dataset, see Table 2A in the Supporting Information File 
Table 1 Summary of variables and descriptive statistics (all countries, 2005-2019)

\begin{tabular}{|c|c|c|c|c|c|c|}
\hline Variable & Description & Mean & Std. dev. & Min & Max & N. of obs. \\
\hline QSD & Soft drink consumption per capita (litres/person/year) & 75.21 & 49.22 & 1.69 & 270.95 & 1470 \\
\hline$O B E$ & Prevalence of obesity (BMI $\geq 30 \mathrm{~kg} / \mathrm{m}^{2}$. Age-stand. Rate, both sexes, $18+$ years, \%) & 18.44 & 8.65 & 0.90 & 38.50 & 1455 \\
\hline OWE & Prevalence of overweight (BMI $\geq 25 \mathrm{~kg} / \mathrm{m}^{2}$. Age-stand. Rate, both sexes, $18+$ years, \%) & 49.20 & 15.35 & 12.2 & 73.5 & 1440 \\
\hline PSD & Soft drink price (average per litre PPP, constant 2017 international \$) & 3.44 & 1.23 & 1.58 & 15.12 & 1470 \\
\hline GNI & Gross national income per capita (PPP, constant 2017 international \$) & $23,993.90$ & $19,745.52$ & 892.83 & $97,094.19$ & 1455 \\
\hline DES & Dietary energy supply (kcal/person/day) & 2984.00 & 421.89 & 1729 & 3847 & 1470 \\
\hline URB & Urban population (as \% of total population) & 65.01 & 20.06 & 15.70 & 100.00 & 1455 \\
\hline$A G E$ & Population aged 65 and above (as \% of total population) & 10.25 & 6.14 & 0.69 & 28.00 & 1455 \\
\hline GLO & KOF Index of economic globalisation $(\min =0, \max =100)$ & 63.08 & 15.79 & 25.5 & 95.3 & 1455 \\
\hline
\end{tabular}

Notes: BMI: Body mass index; PPP: Purchasing power parity; KOF: Swiss Economic Institute

S1. The dataset is also publicly available at Mendeley Data (https://doi.org/10.17632/hkm25rbpsc.2).

\section{Regression model}

Using the above-described set of variables, we can rewrite the system of simultaneous Eqs. 1) and 2) as follows:

$$
\begin{aligned}
Q S D_{i t}= & \alpha_{0}+\alpha_{1} O B E_{i t}+\alpha_{2} P S D_{i t}+\alpha_{3} G N I_{i t} \\
& +\alpha_{4} A G E_{i t}+\alpha_{5} G L O_{i t}+\alpha_{i}+u_{i t} . \\
O B E_{i t}= & \beta_{0}+\beta_{1} Q S D_{i t}+\beta_{2} D E S_{i t}+\beta_{3} U R B_{i t} \\
& +\beta_{4} A G E_{i t}+\beta_{5} G L O_{i t}+\beta_{i}+u_{i t} .
\end{aligned}
$$

where the subscripts $i$ and $t$ refer to the country and year, respectively. The consumption of soft drinks and the prevalence of obesity tend to vary greatly across and within countries, even among countries with similar economic characteristics. Because several cultural and social unobserved factors may affect both $Q S D$ and $O B E$, a fixed-effects regression model was used to control for potential country-specific omitted variables. Thus, $\alpha_{i}$ and $\beta_{i}$ in Eqs. 3) and 4) denote the time-invariant countryspecific constant (i.e. the country- specific fixed effects representing unobserved heterogeneity).

The structural Eqs. 3) and 4) describe a system in which $Q S D$ and $O B E$ are jointly determined (i.e. soft drink consumption and the prevalence of obesity are both endogenous variables). This system thus violates the classical assumption of independence between the error term and the explanatory variables. Applying ordinary least squares (OLS) directly to the structural equations of such a simultaneous system produces biased estimates because OLS regression is likely to attribute to the explanatory variable variations in the dependent variable that are actually being caused by variations in the error term. We adopted a Two-Stage Least Squares (2SLS) estimation technique to mitigate the effects of this simultaneity bias [38].
In the first stage, the 2SLS technique uses a linear combination of all the exogenous variables in the system to produce predicted values of the endogenous variables. In the second stage, these predicted values are utilised to replace the endogenous variables, where they appear on the right-hand side of each structural equation. In the first stage, the exogenous variables are thus used as instrumental variables. Valid instrumental variables must be relevant (i.e. a good proxy of the endogenous variables) and exogenous (i.e. uncorrelated with the error term). The Underidentification test is used to check the relevance of the instruments. It determines whether the variation in the instruments is related to the variation in the endogenous variables. The Sargan-Hansen J-statistic refers to the exogeneity of the instrumental variables and tests whether the instruments are correlated with the estimated residuals (i.e. it tests if that part of the variation of the endogenous variable captured by the instrumental variables is exogenous) [38].

Finally, identification is a precondition for the application of 2SLS. Specifically, a structural equation is identified only when enough of the system's predetermined variables are omitted from the equation in question to allow that equation to be distinguished from all the others in the system' ([39] , p. 430). Both Eqs. 3) and 4) satisfy the necessary condition to be identified (that is, the number of exogenous variables in the system is greater than the number of slope coefficients of each equation). Regression analysis was performed in Stata version 16.1 (Stata Corp LLC, Texas, USA), using the command' xtivreg2' to run panel data instrumental variables regressions (and the commands' fe' and 'robust' to control for country fixed effects and heteroskedasticity, respectively).

\section{Results}

The results of the regression analysis, as summarised in Table 2, indicate the existence of a vicious cycle between 
Table 2 Regression results (2SLS): Obesity, all countries

\begin{tabular}{|c|c|c|c|c|c|c|c|}
\hline \multicolumn{4}{|c|}{ Dependent variable: Soft drink consumption, QSD } & \multicolumn{4}{|c|}{ Dependent variable: Prevalence of obesity, $O B E$} \\
\hline \multicolumn{2}{|l|}{ Independent variables } & \multirow{2}{*}{$\begin{array}{l}\text { Coefficient } \\
2.390^{* * *}\end{array}$} & \multirow{2}{*}{$\begin{array}{l}\text { Std. Error }^{1} \\
0.233\end{array}$} & \multicolumn{2}{|l|}{ Independent variables } & \multirow{2}{*}{$\begin{array}{l}\text { Coefficient } \\
0.069^{* *}\end{array}$} & \multirow{2}{*}{$\begin{array}{l}\text { Std. Error }^{1} \\
0.024\end{array}$} \\
\hline Prevalence of obesity & $O B E$ & & & Soft drink consumption & QSD & & \\
\hline Soft drink price & PSD & $-2.003^{* * *}$ & 0.562 & Dietary energy supply & DES & $2.913^{* * *}$ & 0.667 \\
\hline Income per capita & GNI & $0.737^{* * *}$ & 0.157 & Urban population & URB & $0.389^{* * *}$ & 0.042 \\
\hline Population aged 65 and above & $A G E$ & $-5.212^{* * *}$ & 0.496 & Population aged 65 and above & AGE & $1.043^{* * *}$ & 0.075 \\
\hline Economic globalisation & GLO & $0.348^{* * *}$ & 0.089 & Economic globalisation & GLO & $-0.045^{*}$ & 0.017 \\
\hline N. of obs. & \multicolumn{3}{|l|}{1440} & N. of obs. & \multicolumn{3}{|c|}{1440} \\
\hline F-statistic, F(5, 1339) & \multicolumn{3}{|c|}{ 53.85, Prob. 0.000} & F-statistic, F(5, 1339) & \multicolumn{3}{|c|}{ 304.70, Prob. 0.000} \\
\hline Underidentification test & \multicolumn{3}{|c|}{ 188.60, P-val. 0.000} & Underidentification test & \multicolumn{3}{|c|}{ 66.89, P-val. 0.000} \\
\hline Weak identification test & \multicolumn{3}{|c|}{497.31} & Weak identification test & \multicolumn{3}{|c|}{63.32} \\
\hline Sargan-Hansen J statistic & \multicolumn{3}{|c|}{ 0.077, P-val. 0.782} & Sargan-Hansen J statistic & \multicolumn{3}{|c|}{0.049, P-val. 0.824} \\
\hline
\end{tabular}

Notes: 2SLS: Two-stage least square estimation, with fixed effects

${ }^{1}$ Heteroskedasticity-robust standard errors. ${ }^{*},{ }^{*}$ and ${ }^{* * *}$ denote $p<0.05, p<0.01$ and $p<0.001$, respectively

Underidentification test (Kleibergen-Paap rk LM statistic), Weak identification test (Cragg-Donald Wald F statistic),

Sargan-Hansen J statistic (overidentification test of all instruments)

the consumption of soft drinks and the prevalence of obesity. The left-hand side of Table 2 collects the regression results based on Eq. 3), in which the dependent variable is $Q S D$. All explanatory variables were statistically significant and displayed the expected sign. Specifically, changes in the spread of obesity were associated with changes in soft drink consumption. Holding fixed all other factors affecting $Q S D$, a one-unit increase in the age-adjusted prevalence rate of obesity increased the consumption of soft drinks by about 2.391 per person per year.

Soft drink consumption also responded to changes in both price and income per capita. A one-unit increase in the average price per litre was associated with a decrease in the quantity consumed by around 21 (per person per year). Conversely, consumption increased by about 0.7 units for each $\$ 1000$ of additional income per capita, denoting soft drinks as normal goods whose consumption moves in the same direction as income. Moreover, soft drink consumption was inversely related to population aging (i.e. QSD decreased by 5.21 for every $1 \%$ increase in the share of people aged 65 or more in the total population). Finally, globalisation showed a positive relationship with soft drink consumption, which increased by about 0.351 (per person per year) for every one-unit increase in the degree of economic globalisation as measured by the $K O F$ index.

The left-hand side of Table 2 displays the regression results based on Eq. 4), in which the dependent variable is $O B E$. As the consumption of soft drinks rose, so did the prevalence of obesity. Specifically, the age-adjusted rate of obesity increased by $0.07 \%$ for every additional litre consumed per capita. The impact of $Q S D$ on $O B E$ was statistically significant. Furthermore, the prevalence of obesity also increased with the amount of energy available for human consumption (DES), the share of urban population $(U R B)$, and the share of elderly people $(A G E)$, as expected. In contrast, the impact of the degree of economic globalisation was slightly negative $(-0.04)$ and also less statistically significant. However, this unexpected sign is consistent with recent research on the effects of globalisation on the spread of obesity, which has documented a complex chain of relationships between obesity and the globalisation process [37].

Results of the statistical tests on the instrumental variables are reported in the bottom lines of Table 2 . In both equations, we rejected the null hypothesis that the equations were underidentified, so the instruments chosen were relevant. In addition, we found a first-stage F-statistic larger than the Stock-Yogo critical values in the weak identification test, suggesting that our instruments were not weak. Finally, the $p$ values of the J-statistic for the overidentification test of all instruments for Eqs. 3) and 4) were 0.78 and 0.82 , respectively. These results indicate that we cannot reject the null hypothesis that the instrumental variables were valid (i.e. uncorrelated with the error term in the second stage).

Finally, two sensitivity tests were performed. First, we tested the model using the prevalence of overweight $(O W E)$. Second, we divided countries into two groups: high-income countries and low- and middle-income countries (that is, low, lower-middle, and upper-middleincome countries), according to the World Bank's classification of countries by income levels [40].

The results of the first test are collected in Table 3 and confirm the interplay between soft drink consumption and the prevalence of overweight. Moreover, the impact of a one-unit increase in the prevalence of 
Table 3 Regression results (2SLS): Overweight, all countries

\begin{tabular}{|c|c|c|c|c|c|c|c|}
\hline \multicolumn{4}{|c|}{ Dependent variable: Soft drink consumption, QSD } & \multicolumn{4}{|c|}{ Dependent variable: Prevalence of overweight, OWE } \\
\hline \multicolumn{2}{|l|}{ Independent variables } & \multirow{2}{*}{$\begin{array}{l}\text { Coefficient } \\
1.576^{* * *}\end{array}$} & \multirow{2}{*}{$\begin{array}{l}\text { Std. Error }{ }^{1} \\
0.142\end{array}$} & \multicolumn{2}{|c|}{ Independent variables } & \multirow{2}{*}{$\begin{array}{l}\text { Coefficient } \\
0.119^{* * *}\end{array}$} & \multirow{2}{*}{$\begin{array}{l}\text { Std. Error } \\
0.025\end{array}$} \\
\hline Prevalence of overweight & OWE & & & Soft drink consumption & QSD & & \\
\hline Soft drink price & $P S D$ & $-1.744^{* * *}$ & 0.546 & Dietary energy supply & DES & $4.259^{* * *}$ & 0.717 \\
\hline Income per capita & GNI & $0.751^{* * *}$ & 0.136 & Urban population & URB & $0.590^{* * *}$ & 0.042 \\
\hline Population aged 65 and above & $A G E$ & $-4.602^{* * *}$ & 0.410 & Population aged 65 and above & $A G E$ & $1.199^{* * *}$ & 0.073 \\
\hline Economic globalisation & GLO & $0.329^{* * *}$ & 0.084 & Economic globalisation & GLO & $-0.062^{* * *}$ & 0.017 \\
\hline N. of obs. & \multicolumn{3}{|l|}{1440} & N. of obs. & \multicolumn{3}{|l|}{1440} \\
\hline F-statistic, F(5, 1339) & \multicolumn{3}{|c|}{ 61.14, Prob. 0.000} & F-statistic, $F(5,1339)$ & \multicolumn{3}{|c|}{ 616.46, Prob. 0.000} \\
\hline Underidentification test & \multicolumn{3}{|c|}{ 262.73, P-val. 0.000} & Underidentification test & \multicolumn{3}{|c|}{ 66.90, P-val. 0.000} \\
\hline Weak identification test & \multicolumn{3}{|c|}{$13,014.05$} & Weak identification test & \multicolumn{3}{|c|}{63.31} \\
\hline Sargan-Hansen J statistic & \multicolumn{3}{|c|}{ 0.079, P-val. 0.778} & Sargan-Hansen J statistic & \multicolumn{3}{|c|}{ 1.295, P-val. 0.255} \\
\hline
\end{tabular}

Notes: 2SLS: Two-stage least square estimation, with fixed effects

${ }^{1}$ Heteroskedasticity-robust standard errors. ${ }^{* *}$ denotes $p<0.001$, respectively

Underidentification test (Kleibergen-Paap rk LM statistic), Weak identification test (Cragg-Donald Wald F statistic),

Sargan-Hansen J statistic (overidentification test of all instruments)

overweight on consumption and, vice-versa, the impact of a one-unit increase in consumption on the prevalence of overweight were, respectively, smaller $(1.57<2.39)$ and greater $(0.12>0.07)$ than that of obesity, as expected. The statistical tests on the instrumental variables showed that the instruments used were both relevant and exogenous.

The results of the second test, collected in Tables 4 and 5 , show that the two-way relationship between consumption $(Q S D)$ and obesity $(O B E)$ was consistent across both income groups. It is worth noting that in low- and middle-income countries, the impact of a oneunit increase in the prevalence of obesity on the consumption of soft drinks was greater than that observed in high-income countries (1.8 and $1.1 \mathrm{l}$, respectively). Conversely, a one-unit increase in soft drink consumption increased the prevalence of obesity by about the same amount (around 0.06\%) in both groups, as expected. According to all post-estimation tests, the variables chosen were valid instruments and the model was always correctly identified (only in the demand equation for the group of low- and middle-income countries, the overidentification test did not provide the expected result, denoting that one of the instruments was slightly weak).

\section{The interplay between soft drinks and obesity}

The public health implications of the interdependency between the consumption of soft drinks and the prevalence of obesity are summarised in Fig. 2. The horizontal axis measures the per capita consumption of soft drinks $(Q S D)$, and the vertical axis measures the prevalence of obesity $(O B E)$. To simplify, let us consider linear relationships. The impact of soft drink consumption on the spread of obesity (i.e. Eq. 2)) is shown by the solid red curve labelled $O B E(Q S D)$. This function is upward

Table 4 Regression results (2SLS): Obesity, high-income countries

\begin{tabular}{|c|c|c|c|c|c|c|c|}
\hline \multicolumn{4}{|c|}{ Dependent variable: Soft drink consumption, QSD } & \multicolumn{4}{|c|}{ Dependent variable: Prevalence of obesity, $O B E$} \\
\hline \multicolumn{2}{|c|}{ Independent variables } & \multirow{2}{*}{$\begin{array}{l}\text { Coefficient } \\
1.084^{* *}\end{array}$} & \multirow{2}{*}{$\begin{array}{l}\text { Std. Error }^{1} \\
0.406\end{array}$} & \multicolumn{2}{|c|}{ Independent variables } & \multirow{2}{*}{$\begin{array}{l}\text { Coefficient } \\
0.061^{* *}\end{array}$} & \multirow{2}{*}{$\begin{array}{l}\text { Std. Error } \\
0.022\end{array}$} \\
\hline Prevalence of obesity & $O B E$ & & & Soft drink consumption & QSD & & \\
\hline Soft drink price & PSD & $-6.764^{* * *}$ & 1.601 & Dietary energy supply & DES & $4.238^{* * *}$ & 1.147 \\
\hline Income per capita & GNI & $0.757^{* * *}$ & 0.150 & Urban population & $U R B$ & $0.553^{* * *}$ & 0.043 \\
\hline Population aged 65 and above & AGE & $-4.301^{* * *}$ & 0.680 & Population aged 65 and above & AGE & $1.001^{* * *}$ & 0.078 \\
\hline Economic globalisation & GLO & $0.515^{* *}$ & 0.175 & Economic globalisation & GLO & $-0.081^{* *}$ & 0.025 \\
\hline N. of obs. & \multicolumn{3}{|l|}{859} & N. of obs. & \multicolumn{3}{|l|}{859} \\
\hline F-statistic, F(5, 790) & \multicolumn{3}{|c|}{ 21.41, Prob. 0.000} & F-statistic, F(5, 790) & \multicolumn{3}{|c|}{ 233.48, Prob. 0.000} \\
\hline Underidentification test & \multicolumn{3}{|c|}{ 78.72, P-val. 0.000} & Underidentification test & \multicolumn{3}{|c|}{ 37.59, P-val. 0.000} \\
\hline Weak identification test & \multicolumn{3}{|c|}{310.60} & Weak identification test & \multicolumn{3}{|c|}{47.02} \\
\hline Sargan-Hansen J statistic & \multicolumn{3}{|c|}{ 1.342, P-val. 0.247} & Sargan-Hansen J statistic & \multicolumn{3}{|c|}{0.294, P-val. 0.588} \\
\hline
\end{tabular}


Table 5 Regression results (2SLS): Obesity, non-high-income countries

\begin{tabular}{|c|c|c|c|c|c|c|c|}
\hline \multicolumn{4}{|c|}{ Dependent variable: Soft drink consumption, QSD } & \multicolumn{4}{|c|}{ Dependent variable: Prevalence of obesity, $O B E$} \\
\hline \multicolumn{2}{|c|}{ Independent variables } & \multirow{2}{*}{$\begin{array}{l}\text { Coefficient } \\
1.776^{* * *}\end{array}$} & \multirow{2}{*}{$\begin{array}{l}\text { Std. Error }^{1} \\
0.270\end{array}$} & \multicolumn{2}{|c|}{ Independent variables } & \multirow{2}{*}{$\begin{array}{l}\text { Coefficient } \\
0.058^{* *}\end{array}$} & \multirow{2}{*}{$\begin{array}{l}\text { Std. Error } \\
0.029\end{array}$} \\
\hline Prevalence of obesity & OBE & & & Soft drink consumption & QSD & & \\
\hline Soft drink price & PSD & $-0.628^{*}$ & 0.324 & Dietary energy supply & DES & $2.572^{* * *}$ & 0.548 \\
\hline Income per capita & GNI & $2.780^{* * *}$ & 0.481 & Urban population & URB & $0.389^{* * *}$ & 0.045 \\
\hline Population aged 65 and above & $A G E$ & -1.652 & 1.185 & Population aged 65 and above & $A G E$ & $0.825^{* * *}$ & 0.183 \\
\hline Economic globalisation & GLO & $0.213^{*}$ & 0.086 & Economic globalisation & GLO & $-0.062^{* *}$ & 0.019 \\
\hline N. of obs. & \multicolumn{3}{|l|}{578} & N. of obs. & \multicolumn{3}{|l|}{578} \\
\hline F-statistic, F(5, 530) & \multicolumn{3}{|c|}{ 85.95, Prob. 0.000} & F-statistic, F(5, 530) & \multicolumn{3}{|c|}{ 193.15, Prob. 0.000} \\
\hline Underidentification test & \multicolumn{3}{|c|}{ 77.41, P-val. 0.000} & Underidentification test & \multicolumn{3}{|c|}{ 31.36, P-val. 0.000} \\
\hline Weak identification test & \multicolumn{3}{|c|}{167.47} & Weak identification test & \multicolumn{3}{|c|}{45.41} \\
\hline Sargan-Hansen J statistic & \multicolumn{3}{|c|}{ 7.303, P-val. 0.007} & Sargan-Hansen J statistic & \multicolumn{3}{|c|}{0.164, P-val. 0.685} \\
\hline
\end{tabular}

Notes: Tables 4 and 5. 2SLS: Two-stage least square estimation, with fixed effects

${ }^{1}$ Heteroskedasticity-robust standard errors. ${ }^{*},{ }^{*}$ and ${ }^{* * *}$ denote $p<0.05, p<0.01$ and $p<0.001$, respectively Underidentification test (Kleibergen-Paap rk LM statistic), Weak identification test (Cragg-Donald Wald F statistic),

Sargan-Hansen J statistic (overidentification test of all instruments)

sloping, showing that an increase in the amount of soft drink consumed by the population (i.e. a rightward movement along the $\mathrm{x}$-axis) leads to an increase in the prevalence of obesity.

Conversely, the impact of the prevalence of obesity on soft drink consumption (i.e., Eq. 1)) is shown by the solid blue curve labelled $Q S D\left(O B E, z_{1}\right)$. This functionplotted in the space $(Q S D, O B E)$ for ease of demonstration-is also upward sloping because a higher prevalence of obesity among the population (i.e. an upward movement on the $y$-axis) leads to a higher demand for soft drinks. In this context, $Q S D$ and $O B E$ are jointly determined. The adoption of unhealthy eating habits (i.e. the consumption of soft drinks) and the spread of their adverse health outcomes (i.e. the prevalence of obesity)

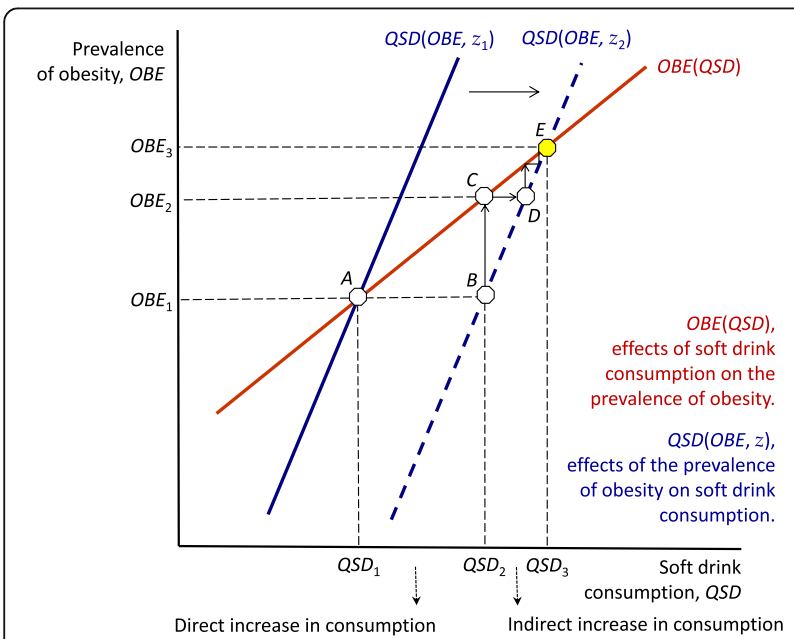

Fig. 2 Interplay between soft drink consumption and the prevalence of obesity. Legends: QSD, litres/person/year. OBE, age-stand. Rate, both sexes, $18+$ years, $\%$ influence each other, determining the observed levels of consumption and obesity $\left(Q S D_{1}\right.$ and $O B E_{1}$, at point $\mathrm{A}$ in Fig. 2).

This simplified diagram helps us to better understand the nature of this self-reinforcing process that links the consumption of soft drinks and the prevalence of obesity. Let us consider, for instance, an emerging economy where an increasing per capita income drives a process of nutrition transition from traditional to ultraprocessed foods and beverages. In Fig. 2, we denote with $z$ a catchall variable that stands for all factors, other than the prevalence of obesity, affecting soft drink consumption (such as the price of soft drinks, consumers' income, tastes etc.). Thus, a change in $z$ (for example, from $z_{1}$ to $z_{2}$ ), as a result of the new (and unhealthy) dietary habits, shifts the entire curve $Q S D(O B E, z)$ to the right, indicating higher soft drink consumption, at any given prevalence of obesity.

Specifically, $Q S D(O B E, z)$ shifts from the original solid blue curve $Q S D\left(O B E, z_{1}\right)$ to the new dotted blue curve $Q S D\left(O B E, z_{2}\right)$. If there were no effects of the prevalence of obesity on the consumption of soft drinks, the increase in $Q S D$ would simply match the effect of the new dietary pattern. This direct impact is shown by the movement from point A to point B in Fig. 2, which implies an increase in soft drink consumption from $Q S D_{1}$ to $Q S D_{2}$. However, this is not the end of the story. Such an increase in $Q S D$ triggers a feedback loop between consumption and obesity. Given the impact of soft drink consumption on the prevalence of obesity-i.e. given the $O B E(Q S D)$ red curve-a higher level of consumption leads to an increase in the prevalence of obesity.

More specifically, the rise of consumption per capita from $Q S D_{1}$ to $Q S D_{2}$ increases the prevalence of obesity among the population from $O B E_{1}$ to $O B E_{2}$ (shown, in 
Fig. 2, by the upward movement from point B to point C). In turn, an increase in the spread of obesity implies a higher share of consumers with unhealthy dietary habits. Thus, it promotes a further increase in the consumption of soft drinks (the rightward movement from point $\mathrm{C}$ to point $\mathrm{D})$. Again, this leads to a further increase in the prevalence of obesity, and so forth. This process continues, increasing consumption and obesity, until both converge on their new equilibrium levels, $\mathrm{QSD}_{3}$ and $O B E_{3}$ at point $\mathrm{E}$.

In other words, the vicious cycle that links the adoption of unhealthy dietary patterns and the spread of obesity amplifies the impact of any exogenous change in either or both consumption and obesity. In the case shown in Fig. 2, in response to the initial change in consumption from $Q S D_{1}$ to $Q S D_{2}$, obesity increases from $O B E_{1}$ to $O B E_{3}$, and consumption increases from $Q S D_{1}$ to $Q S D_{3}$. This increase in consumption is the sum of two components: the initial direct effect $\left(Q S D_{1}\right.$ to $\left.Q S D_{2}\right)$ plus an indirect effect due to the mutual interaction between $Q S D$ and $O B E$, measured by the increase from $Q S D_{2}$ to $Q S D_{3}$. Similarly, this framework allows analysis of the direct and indirect effects of an exogenous change in the prevalence of obesity for any given level of soft drink consumption due, for instance, to the spread of sedentary lifestyles as a result of the pervasive diffusion of new technologies.

\section{Impact multipliers}

A simultaneous equation model can also be written through reduced-form equations, which express each endogenous variable solely in terms of all the exogenous variables in the system. To this end, using the results collected in Table 2, we rewrite the theoretical regression Eqs. 3) and 4) into their corresponding estimated equations:

$$
\begin{aligned}
Q S D_{i t}= & 2.39 O B E_{i t}-2.00 P S D_{i t} \\
& +0.74 G N I_{i t}-5.21 A G E_{i t}+0.35 G L O_{i t} . \\
O B E_{i t}= & 0.07 Q S D_{i t}+2.91 D E S_{i t}+0.39 U R B_{i t} \\
& +1.04 A G E_{i t}-0.04 G L O_{i t} .
\end{aligned}
$$

(where the estimated coefficients are rounded to two decimal places for conciseness). Then, we substitute Eq. 6) into 5) and vice-versa. We thus solve the resulting equations for $Q S D$ and $O B E$ respectively, so as to obtain the following reduced-form equations:

$$
\begin{aligned}
\mathrm{QSD}_{i t}= & -2.40 P S D_{i t}+0.88 G N I_{i t}-3.26 A G E_{i t} \\
& +0.29 G L O_{i t}+8.34 D E S_{i t}+1.11 U R B_{i t} .
\end{aligned}
$$

$$
\begin{aligned}
O B E_{i t}= & -0.17 P S D_{i t}+0.06 G N I_{i t} \\
& +0.82 A G E_{i t}-0.02 \mathrm{GLO}_{i t}+3.49 D E S_{i t} \\
& +0.47 U R B_{i t} .
\end{aligned}
$$

The coefficients in the estimated Eqs. 5) and 6) are slope parameters. They measure the response of $Q S D$ (or $O B E$ ) to a one-unit increase in the corresponding explanatory variable, holding constant the influence of any other explanatory variables. Instead, the coefficients in Eqs. 7) and 8) are impact multipliers. Each of these coefficients measures the impact on the endogenous variable of a one-unit increase in the value of the corresponding exogenous variable after allowing for the feedback effects from the entire simultaneous system [39].

By comparing slope parameters and impact multipliers, we can assess the role played by the interdependent relationship that links consumption and obesity in promoting the development of an obesogenic food environment. For instance, as documented in the Results section, the direct effect of a one-unit decrease in the average price of soft drinks is an increase in consumption of two litres per person per year. However, the lower price-due, for example, to an aggressive pricing strategy of producers or distributors-leads not only to greater consumption but also to an increase in the spread of obesity, triggering the vicious cycle described in Fig. 2.

The ultimate outcome of a one-unit decrease in $P S D$ is twofold: a growth of around $0.17 \%$ in the prevalence of obesity (Eq. 8)), and a growth in the consumption of soft drinks of around 2.41 per person (Eq. 7)), that is, a final quantity consumed that is greater than the initial increase caused directly by the price reduction. Thus, the difference between the impact multiplier of PSD in Eq. 7) and the slope parameter of PSD in Eq. 5) - that is, $2.4-2.0=0.4-$ measures the indirect impact of a price change on consumption. That is to say, the feedback loop between soft drinks and obesity adds 0.41 of extra consumption for every one-unit decrease in the average price of soft drinks.

\section{Discussion}

Existing studies have examined the association between soft drinks and obesity using cross-country datasets [2023]. Our results are in line with those observed in these previous studies. In reviewing the literature, however, we found very little about a feedback process in which the consumption of soft drinks and the prevalence of obesity interact and reinforce each other. This work was designed to investigate the hypothesis that the consumption of calorie-dense beverages and the prevalence of obesity are jointly determined. We found that soft drinks and obesity are linked in a vicious cycle. This result 
indicates that the development of obesogenic food environments should be considered as a self-reinforcing process.

Although the purpose of this study was to document whether and to what extent dietary habits and weight outcomes influence each other, we attempt to introduce some hypotheses about the potential mechanisms behind this vicious cycle. In the food industry, firms engage in both price and non-price competition. For those firms that produce ultra-processed foods and beverages, product development is a crucial strategy of non-price competition [41]. In order to increase product differentiation, this strategy is often based on the improvement of palatability (i.e. the positive hedonic evaluation of foods' characteristics) and, more generally, on the improvement of the product's sensory properties (such as sight, smell, taste, and texture), by adding sugars, fats, salt, and various additives during processing [42].

In other words, this kind of competition tends to increase the number and variety of highly palatable and unhealthy calorie-dense foods and beverages [43]. Usually, such products are not only nutritionally unbalanced but also habit-forming (or even addictive) [44]. As a result, the interaction between firms' strategies and consumers' preferences triggers a vicious cycle. The wide availability of convenient and affordable unhealthy products promotes the adoption of unhealthy dietary patterns. In turn, the regular consumption of these habitforming foods and beverages shapes consumers' tastes and purchasing behaviours, thereby increasing the demand for unhealthy products, and so on.

In the case of soft drinks, these products are usually the largest source of calories and added sugar in the diet of millions of people, especially in high- and middleincome countries $[45,46]$. There is strong evidence that the regular consumption of soft drinks increases the risk of overweight and obesity among children, adolescents, and adults [16]. Research has also shown the potentially addictive properties of the high amount of sugar contained in the large majority of soft drinks $[47,48]$. Furthermore, recent studies in behavioural sciences suggest the existence of a vicious cycle between obesity and cognitive dysfunction $[49,50]$. This vicious cycle is triggered by adopting a Western diet, mainly based on energydense foods and beverages (such as SSBs). It results in the following sequence: overconsumption of unhealthy ultra-processed products, positive energy balance, hippocampal dysfunction, impaired inhibitory cognitive control of responding to environmental food cues, further overconsumption of unhealthy products, and so forth. We also know [51] that obese patients face barriers to change their eating habits towards healthy diets (such as lack of willpower, time constraints, taste preferences, and the pervasive availability of unhealthy foods and beverages). From the demand side, this implies that the increase in the prevalence of obesity, caused by the regular consumption of soft drinks, creates the ideal conditions for further market expansions, promoting the consumption of soft drinks and other calorie-dense products in the everyday diet. From the supply side, this vicious cycle is further reinforced by the price and nonprice strategies of the beverage industry that increase affordability and availability of a wide range of soft drinks, enhancing the development of an obesogenic food environment.

From a public health perspective, our results further support the use of fiscal policies, such as taxes on sugarsweetened beverages (SSBs), to curb the consumption of these calorie-dense products [52]. Specifically, the identification of a feedback loop involving consumption and obesity may imply that the long-run effects on the prevalence of obesity of an excise tax (that raises the market price of SSBs) are probably currently underestimated.

Some recent papers have tried to model the potential impacts of 'sugar taxes' on health outcomes. Albeit based on the single causal relationship between consumption and obesity (and limited to simulation studies), these papers have consistently shown that taxes can lead to reductions in incident rates of obesity [53]. However, taxes on SSBs are designed to decrease consumption but also to raise public awareness, incentive product reformulation, and generate government revenue (to be used, for instance, to implement nutrition education programs). Conversely, considering the two-way interplay between consumption and obesity, one can see that all these potential outcomes shift either or both the $Q S D(O B E)$ and $O B E(Q S D)$ relationships. For instance, despite the small direct impact of $Q S D$ on $O B E$ (i.e. one-litre change in per capita consumption of soft drinks will change obesity prevalence by $0.07 \%$ ), the total (direct and indirect) effect on the prevalence of obesity of a one-unit increase in the average price of soft drinks in around 2.5 times larger than that indicated by the slope parameter of the single demand equation model. As a result, introducing a tax on SSBs can trigger a virtuous cycle that amplifies the initial decrease in consumption and obesity.

\section{Limitations}

Several limitations need to be noted regarding the results of the regression analysis. First, the consumption of soft drinks and the prevalence of obesity are affected by many factors. Our empirical model is based on a very small set of variables. This limitation is mainly due to a lack of data. For many countries, especially low-income countries, no reliable data exist, or the available data span too short a period of time to be used in a balanced panel data set. This leads to a second important 
weakness. Both soft drink consumption and the prevalence of obesity are growing phenomena in low- and lower-middle-income countries [54, 55]. Our dataset, however, included only three low-income countries and 23 lower-middle-income countries (conversely, it included 72 upper-middle and high-income countries, as shown in Table 1A in the Supporting Information File S1). Third, for the same reasons (i.e. data availability), we were not able to account for the effects of income inequalities on dietary patterns and health outcomes even within upper-middle and high-income countries.

Furthermore, data on the dependent variables (i.e. the prevalence of overweight/obesity, and the consumption of soft drinks) are not fully comparable. The variables $O B E$ and $O W E$ are estimated from population-based data [56], whereas $Q S D$ comes from sales data that are only a proxy of the effective consumption, due to the increasing phenomenon of food waste [57]. In addition, QSD measures sales per capita of a wide range of beverages that contain very different quantities of free sugars (e.g. some regular sodas contain less than $10 \mathrm{~g}$ of sugar per eight oz. serving, and others more than $45 \mathrm{~g}$ ) [58]. Moreover, in recent years, taxes on sugar-sweetened beverages have been implemented in more than 35 countries worldwide [52, 53], and, more generally, many countries have implemented obesity prevention programs [7]. These national food policies are a potential confounding factor in the interplay between soft drinks and obesity, because they may lead to exogenous shifts in both $Q S D(O B E)$ and $O B E(Q S D)$ relationships.

Another potential weakness comes from the use of a country fixed effects model, which did not allow us to control for variables that change over time. However, random effects models are based on more stringent assumptions and are more challenging to estimate and interpret. Therefore, as a first attempt to study soft drink consumption and the prevalence of obesity within a simultaneous equation model, we preferred to be more conservative and control only for country-specific fixed effects. Finally, we found associations that did not necessarily indicate the existence of cause-and-effect relationships, and the use of country-level data offered the potential for ecological fallacies. However, this is the first study to document a two-way relationship between soft drinks and obesity. Further research should be undertaken to apply a simultaneous equation model to individual data, using a broader range of control variables and different types of ultra-processed foods and beverages.

\section{Conclusions}

Obesity is a complex and multifactorial disease. The onset of obesity, however, is largely preventable. Relatively simple changes in dietary habits and physical activity effectively help to maintain a healthy weight, reducing the risk of developing one or more obesity-related diseases [59]. Nevertheless, dietary habits are strongly influenced by the food environment within which people make their everyday consumption choices. Making healthy choices is challenging within obesogenic food environments, where affordable, convenient, nutritionally unbalanced, hyper-palatable, and habit-forming ultra-process foods and beverages are ubiquitous and aggressively marketed. However, the development of an obesogenic environment is itself both a cause and an effect of the spread of unhealthy habits and behaviours. This study has identified a vicious cycle between unhealthy habits (i.e. consuming soft drinks) and health outcomes (i.e. the prevalence of obesity). We documented that the consumption of soft drinks and the prevalence of obesity influence each other. This interplay amplifies the impact of any exogenous changes in the determinants of consumption and obesity. A change in the price of soft drinks, for instance, affects not only the quantity consumed but also the spread of obesity, leading to an overall change in consumption greater than the one due to the direct effect of the initial price change. These feedback effects should be considered and exploited in planning effective strategies to tackle the burden of obesity and the NCDs epidemic.

\section{Supplementary Information}

The online version contains supplementary material available at https://doi. org/10.1186/s12992-021-00735-y.

Additional file 1. List of variables. Table 1A. List of countries included in the study by income group. Table 2A. Dataset.

\section{Acknowledgements}

We would like to thank the anonymous reviewers for their constructive comments and suggestions, which greatly enriched our contribution. All remaining errors are our own.

\section{Authors' contributions}

Fabrizio Ferretti: conceived and designed the study, collected the data, performed the experiments, analysed and interpreted the results, and wrote the paper. Elena Sarti: performed the experiments, analysed and interpreted the results, and wrote the paper. Michele Mariani: analysed and interpreted the results and wrote the paper. All authors read and approved the final manuscript.

\section{Funding}

The authors received no financial support for the research, authorship, and publication of this article.

\section{Availability of data and materials}

We used secondary data. All data generated or analysed during this study are included in this published article and in the Supporting Information File S1. The full dataset is also publicly available at Mendeley Data (https://doi. org/10.17632/hkm25rbpsc.2).

\section{Declarations}

Ethics approval and consent to participate Not applicable. 


\section{Consent for publication}

Not applicable.

\section{Competing interests}

The authors declare that they have no competing interests.

Received: 26 April 2021 Accepted: 9 July 2021

Published online: 18 August 2021

\section{References}

1. World Health Organization. Obesity and overweight. Fact sheet. 2020. http://www.who.int/news-room/fact-sheets/detail/obesity-andoverweight. Accessed 5 Mar 2021.

2. Zhao X, Gang X, He G, Li Z, Lv Y, Han Q, et al. Obesity increases the severity and mortality of influenza and COVID-19: a systematic review and metaanalysis. Front Endocrinol. 2020;21:11. https://doi.org/10.3389/fendo.2020. 595109

3. Hruby A, Hu FB. The epidemiology of obesity: a big picture. PharmacoEconomics. 2014;33(7):673-89. https://doi.org/10.1007/s40273-0140243-x.

4. Giskes K, van Lenthe F, Avendano-Pabon M, Brug J. A systematic review of environmental factors and obesogenic dietary intakes among adults: are we getting closer to understanding obesogenic environments? Obes Rev. 2010; 12(5):e95-e106. https://doi.org/10.1111/j.1467-789x.2010.00769.x

5. Lim HJ, Xue H, Wang Y. Global trends in obesity. Handbook of eating and drinking. Springer International Publishing; 2020. p. 1217-35. https://doi. org/10.1007/978-3-030-14504-0_157.

6. Lake A, Townshend TG, Alvanides S, editors. Obesogenic environments: complexities, perceptions, and objective measures. Oxford: Wiley-Blackwell; 2010. https://doi.org/10.1002/9781118786611.

7. Shekar M, Popkin B. Editors. Obesity. Health and economic consequences of an impending global challenge. Washington, DC: The World Bank; 2020. https://doi.org/10.1596/978-1-4648-1491-4

8. Vandevijvere S, Jaacks LM, Monteiro CA, Moubarac J, Girling-Butcher M, Lee $A C$, et al. Global trends in ultraprocessed food and drink product sales and their association with adult body mass index trajectories. Obes Rev. 2019; 20(S2):10-9. https://doi.org/10.1111/obr.12860.

9. Baker P, Machado P, Santos T, Sievert K, Backholer K, Hadjikakou M, Russell C., Huse O., Bell C., Scrinis G., Worsley A., Friel S., Lawrence M. Ultraprocessed foods and the nutrition transition: global, regional and national trends, food systems transformations and political economy drivers. Obes Rev 2020:21(12). https://doi.org/10.1111/obr.13126.

10. Chen X, Zhang Z, Yang H, Qiu P, Wang H, Wang F, Zhao Q, Fang J, Nie J. Consumption of ultra-processed foods and health outcomes: a systematic review of epidemiological studies. Nutr J. 2020;19:86. https://doi.org/10.11 86/s12937-020-00604-1

11. Monteiro CA, Cannon G, Levy RB, Moubarac J-C, Louzada ML, Rauber F, et al. Ultra-processed foods: what they are and how to identify them. Public Health Nutr. 2019;22(5):936-41. https://doi.org/10.1017/s1368980018003762.

12. Monteiro CA, Moubarac J-C, Cannon G, Ng SW, Popkin B. Ultra-processed products are becoming dominant in the global food system. Obes Rev. 2013 Oct 23;14:21-8. https://doi.org/10.1111/obr.12107.

13. Hamid TKA. Thinking in circles about obesity. New York: Springer; 2009. https://doi.org/10.1007/978-0-387-09469-4.

14. Fry C, Spector C, Williamson KA, Mujeeb A. Breaking down the chain: a guide to the soft drink industry. Phoenix: Public health Law \& Policy; 2011.

15. Caballero B. Focus on sugar-sweetened beverages. Public Health Nutr. 2015 Mar 31;18(7):1143-4. https://doi.org/10.1017/s136898001500066x.

16. Hu FB. Resolved: there is sufficient scientific evidence that decreasing sugarsweetened beverage consumption will reduce the prevalence of obesity and obesity-related diseases. Obes Rev. 2013 Jun 13;14(8):606-19. https:// doi.org/10.1111/obr.12040

17. Vartanian LR, Schwartz MB, Brownell KD. Effects of soft drink consumption on nutrition and health: a systematic review and meta-analysis. Am J Public Health. 2007 Apr;97(4):667-75. https://doi.org/10.2105/ajph.2005.083782.

18. Te Morenga L, Mallard S, Mann J. Dietary sugars and body weight: systematic review and meta-analyses of randomised controlled trials and cohort studies. BMJ. 2012;346(jan15 3):e7492. https://doi.org/10.1136/bmj. e7492.
19. An R. Beverage consumption in relation to discretionary food intake and diet quality among US adults, 2003 to 2012. J Acad Nutr Diet. 2016;116(1): 28-37. https://doi.org/10.1016/j.jand.2015.08.009.

20. Basu S, McKee M, Galea G, Stuckler D. Relationship of soft drink consumption to global overweight, obesity, and diabetes: a cross-national analysis of 75 countries. Am J Public Health. 2013 Nov;103(11):2071-7. https://doi.org/10.2105/ajph.2012.300974.

21. Goryakin $Y$, Monsivais $P$, Suhrcke M. Soft drink prices, sales, body mass index and diabetes: evidence from a panel of low-, middle- and high-income countries. Food Policy. 2017 Dec;73:88-94. https://doi.org/10.1016/j. foodpol.2017.09.002.

22. Ferretti F, Mariani M. Sugar-sweetened beverage affordability and the prevalence of overweight and obesity in a cross section of countries. Glob Health. 2019;15:30. https://doi.org/10.1186/s12992-019-0474-x.

23. Ferretti F, Mariani M, Sarti E. Does the prevalence of obesity affect the demand for soft drinks? Evidence from cross-country panel data. Working paper, Jan 21. University of Modena and Reggio Emilia. Submitted to BMC Public Health, under review

24. Popkin BM, Barquera S, Corvalan C, Hofman KJ, Monteiro C, Ng SW et al. Towards unified and impactful policies to reduce ultraprocessed food consumption and promote healthier eating. Lancet Diabetes Endocrinol. 2021;9(7)462-70. https://doi.org/10.1016/s22138587(21)00078-4

25. Euromonitor. Passport Global Market Information Database. Euromonitor International, London. 2020. https://go.euromonitor.com/passport.html. Accessed 3 Mar 2021.

26. The World Bank International Comparison Program (ICP). Washington, DC. The World Bank; 2020. https://www.worldbank.org/en/programs/icp\#1. Accessed 8 Oct 2020.

27. World Health Organization. The Global Health Observatory. Geneva: World Health Organization; 2020. https://www.who.int/data/gho. Accessed 3 Mar 2021.

28. The World Bank. Open Data repository. Washington, DC.: The World Bank; 2020. https://data.worldbank.org/. Accessed 5 Mar 2021.

29. Blecher E, Liber AC, Drope JM, Nguyen B, Stoklosa M. Global trends in the affordability of sugar-sweetened beverages, 1990-2016. Prev Chronic Dis. 2017:4:14. https://doi.org/10.5888/pcd14.160406.

30. Yang L, Bovet $P$, Liu $Y$, Zhao M, Ma C, Liang $Y$, et al. Consumption of carbonated soft drinks among young adolescents aged 12 to 15 years in 53 low- and middle-income countries. Am J Public Health. 2017 Jul;107(7): 1095-100. https://doi.org/10.2105/ajph.2017.303762.

31. Dereń K, Weghuber D, Caroli M, Koletzko B, Thivel D, Frelut M-L, et al. Consumption of sugar-sweetened beverages in paediatric age: a position paper of the European academy of Paediatrics and the European childhood obesity group. Ann Nutr Metab. 2019;74(4):296-302. https://doi.org/10.1159/ 000499828 .

32. Kelly T, Yang W, Chen C-S, Reynolds K, He J. Global burden of obesity in 2005 and projections to 2030. Int J Obes. 2008 Jul 8;32(9):1431-7. https:// doi.org/10.1038/ijo.2008.102.

33. Church T, Martin CK. The obesity epidemic: a consequence of reduced energy expenditure and the uncoupling of energy intake? Obesity. 2017; 26(1):14-6. https://doi.org/10.1002/oby.22072.

34. Food and Agriculture Organisation. FAOSTAT. Rome: Food and Agriculture Organisation; 2020. http://www.fao.org/faostat/en/\#data/FS. Accessed 10 Oct 2020.

35. Gygli S, Haelg F, Potrafke N, Sturm J-E. The KOF globalisation index revisited. Rev Int Organ. 2019 Jan 28;14(3):543-74. https://doi.org/10.1007/ s11558-019-09344-2.

36. Taylor AL, Jacobson MF. Carbonating the world. Washington: Center for Science in the Public Interest, University of Washington; 2016.

37. Fox A, Feng W, Asal V. What is driving global obesity trends? Globalization or "modernization"? Glob Health. 2019;15(1):32. https://doi.org/10.1186/s12 992-019-0457-y.

38. Stock J, Watson M. Introduction to econometrics 4th edition. London: Pearson Education; 2019

39. Studenmund AH. Using econometrics: a practical guide. 7th ed. London: Pearson Education; 2017.

40. The World Bank. World Bank country and lending groups. Washington, DC: The World Bank; 2020. https://datahelpdesk.worldbank.org/knowledgeba se/articles/906519-world-bank-country-and lending-groups. Accessed 25 May 2021. 
41. Gibney MJ. Ultra-processed foods: definitions and policy issues. Curr Dev Nutr. 2018;3(2)nzy077. https://doi.org/10.1093/cdn/nzy077.

42. McCrickerd K, Forde CG. Sensory influences on food intake control: moving beyond palatability. Obes Rev. 2015;17(1):18-29. https://doi.org/10.1111/ obr.12340.

43. Baker P, Friel S. Food systems transformations, ultra-processed food markets and the nutrition transition in Asia. Globalization and Health. 2016;12(1):80. https://doi.org/10.1186/s12992-016-0223-3

44. Gearhardt AN, Hebebrand J. The concept of "food addiction" helps inform the understanding of overeating and obesity: YES. Am J Clin Nutr. 2021; 113(2):263-7. https://doi.org/10.1093/ajcn/nqaa343.

45. Reedy J, Krebs-Smith SM. Dietary sources of energy, solid fats, and added sugars among children and adolescents in the United States. J Am Diet Assoc. 2010;110(10):1477-84. https://doi.org/10.1016/j.jada.2010.07.010.

46. Sánchez-Pimienta TG, Batis C, Lutter CK, Rivera JA. Sugar-sweetened beverages are the main sources of added sugar intake in the Mexican population. J Nutr. 2016;146(9):1888S-96S. https://doi.org/10.3945/jn.115.22 0301.

47. Falbe J, Thompson HR, Patel A, Madsen KA. Potentially addictive properties of sugar-sweetened beverages among adolescents. Appetite. 2019;133:130-7. https:/doi.org/10.1016/j.appet.2018.10.032.

48. Campana B, Brasiel PG, de Aguiar AS, Dutra SCPL. Obesity and food addiction: similarities to drug addiction. Obes Med. 2019;16:100136. https://doi.org/10.1016/j.obmed.2019.100136.

49. Hargrave SL, Jones S, Davidson TL. The outward spiral: a vicious cycle model of obesity and cognitive dysfunction. Curr Opin Behav Sci. 2016;9:40-6. https://doi.org/10.1016/j.cobeha.2015.12.001.

50. Davidson TL, Jones S, Roy M, Stevenson RJ. The cognitive control of eating and body weight: It's more than what you think. Front Psychol. 2019;13:10. https://doi.org/10.3389/fpsyg.2019.00062.

51. Pinho MGM, Mackenbach JD, Charreire H, Oppert J-M, Bárdos H, Glonti K, et al. Exploring the relationship between perceived barriers to healthy eating and dietary behaviours in European adults. Eur J Nutr. 2017;57(5): 1761-70. https://doi.org/10.1007/s00394-017-1458-3.

52. Ferretti F. Sugar-sweetened beverage taxes: origins, mechanisms, and current worldwide status, pp. 851-864 In: Faintuch J, Faintuch S, editors. Obesity and diabetes. 2 ed. Springer; Cham: https://doi.org/10.1007/978-3030-53370-0_63.

53. The World Bank. Taxes on sugar sweetened beverages: International evidence and experiences. Washington, DC: The World Bank; 2020.

54. Singh GM, Micha R, Khatibzadeh S, Shi P, Lim S, Andrews KG, et al. Global, regional, and national consumption of sugar-sweetened beverages, fruit juices, and milk: a systematic assessment of beverage intake in 187 countries. PLoS One. 2015 Aug 5;10(8):e0124845. https://doi.org/10.1371/ journal.pone.0124845.

55. NCD Risk Factor Collaboration (NCD-RisC). Trends in adult body-mass index in 200 countries from 1975 to 2014: a pooled analysis of 1698 populationbased measurement studies with $19 \cdot 2$ million participants. The Lancet. 2016; 387(10026):1377-96. https://doi.org/10.1016/s0140-6736(16)30054-x .

56. Abarca-Gómez L, Abdeen ZA, Hamid ZA, Abu-Rmeileh NM, Acosta-Cazares B, Acuin C, et al. Worldwide trends in body-mass index, underweight, overweight, and obesity from 1975 to 2016: a pooled analysis of 2416 population-based measurement studies in 128.9 million children, adolescents, and adults. Lancet. 2017 Dec;390(10113):2627-42. https://doi. org/10.1016/s0140-6736(17)32129-3.

57. United Nations Environment Programme. Food waste index report 2021. Nairobi: United Nations. 2021.

58. Ventura EE, Davis JN, Goran MI. Sugar content of popular sweetened beverages based on objective laboratory analysis: focus on fructose content Obesity. 2011;19(4):868-74. https://doi.org/10.1038/oby.2010.255.

59. Apovian CM. The obesity epidemic. Understanding the disease and the treatment. N Engl J Med. 2016;374(2):177-9. https://doi.org/10.1056/nejme1 514957.

\section{Publisher's Note}

Springer Nature remains neutral with regard to jurisdictional claims in published maps and institutional affiliations.

Ready to submit your research? Choose BMC and benefit from:

- fast, convenient online submission

- thorough peer review by experienced researchers in your field

- rapid publication on acceptance

- support for research data, including large and complex data types

- gold Open Access which fosters wider collaboration and increased citations

- maximum visibility for your research: over $100 \mathrm{M}$ website views per year

At BMC, research is always in progress.

Learn more biomedcentral.com/submissions 